\title{
PERANCANGAN MEDIA PEMBELAJARAN PADA UNIVERSITAS ISLAM KUANTAN SINGINGI
}

\author{
Jasri 1), Harianja ${ }^{2)}$ \\ ${ }^{1)}$ Fakultas Teknik, Universitas Islam Kuantan Singingi \\ Jl. Gatot Subroto KM. 7 Jake Teluk Kuantan Riau \\ email : jasri.skom@gmail.com \\ ${ }^{2)}$ Fakultas Teknik, Universitas Islam Kuantan Singingi \\ Jl. Gatot Subroto KM. 7 Jake Teluk Kuantan Riau \\ Email : harianja@uniks.ac.id
}

\begin{abstract}
With the advancement of information and communication technology, especially in learning that is not an expert causing technological lags, so the lecturers think the teaching and learning process is more difficult, the huge cost of instructing lecturers to use teaching and learning methods is not in accordance with the times so students are bored with the lecture process. By modeling instructional media, it will be easier for lecturers of the Kuantan Singingi Islamic University to carry out the teaching and learning process, using learning media more easily, using low costs and students will not feel bored. The results of this research can be a facility for lecturers to deliver material and students become active in learning independently both at home and in campus.
\end{abstract}

Keyword : instructional Media, Power Point

\begin{abstract}
Abstrak
Dengan kemajuan teknologi informasi dan komunikasi, terkhusus pada pembelajaran yang bukan ahli menyebabkan katinggalan teknologi, sehingga para dosen berpikir proses belajar mengajar lebih sulit, biaya sangat besar mengakaibatkan para dosen memakai cara belajar mengajar tidak sesuai dengan perkembangan zaman sehingga para mahasiswa bosan dengan proses perkuliahan. Dengan pemodelan media pembelajaran akan memudahkan dosen Universitas Islam Kuantan Singingi untuk melakasanakan proses belajar mengajar, penggunakan media pembelajaran lebih mudah, menggunakan biaya murah dan mahasiswa tidak akan merasa bosan. Hasil dari pnelitian ini dapat menjadi fasilitas dosen menyampaikna materi dan mahasiswa menjadi aktif dalam belajar secara mandiri baik dirumah maupun dikampus.
\end{abstract}

Kata kunci : Media Pembelajaran, Power Point

\section{PENDAHULUAN}

Teknologi merupakan sarana untuk mendukung kebutuhan sehari-hari dan kenyamanan hidup manusia. Penggunaan teknologi oleh manusia diawali dengan pengubahan sumber daya alam menjadi alat-alat sederhana.

Universitas Islam Kuantan Singingi adalah sebuah yayasan yang bergerak dibidang pendidikan, dimana kegiatan sehari-harinya adalah belajar mengajar namun belum maksimal dalam penggunaan teknolgi terutama dalam proses belajar-mengajar masih menggunakan media pembelajaran dengan biasa-biasa saja sehingga menyebabkan bosan yang terjadi pada mahasiswa serta pengajar berpikir pembelajaran menggunakan teknologi 
mempunyai biaya mahal dan sulit untuk menggunakan serta kita bisa mengulangi pelajarannya di manapun.

Media pembelajaran dapat merupakan wahana penyalur pesan dan informasi belajar. Media pembelajaran yang dirancang secara baik akan sangat membantu peserta didik dalam mencerna dan memahami materi pelajaran. Di era globalisasi dan informasi ini, perkembangan media pembelajaran juga semakin maju. (Muhson. A, 2010, Hlm. 1 - 10)

Berdasarkan permasalahan yang ada di Universitas Islam Kuantan Singingi maka penelti mencoba temuan baru dalam pembuatan media pembelajaran mudah digunakan dan menarik untuk dilihat sehingga mehasiswa di Universitas Islam Kuantan Singigni Semangat dalam proses Belajar-mengajar deng judul " Perancangan Media Pembelajaran Pada Universitas Islam Kuantan Singingi”

\section{TINJAUAN PUSTAKA}

\subsection{Definisi Media Pembelajaran}

Media pembelajaran merupakan salah satu komponen pendukung keberhasilan proses belajar mengajar. Selama kegiatan belajar mengajar, dibutuhkan adanya interaksi antara guru dan siswa, agar siswa dapat menyerap materi pelajaran dengan optimal (Srimaya, 2017).

Kata media berasal dari bahasa Latin dan merupakan bentuk jamak dari kata "medium", yang berarti perantara atau pengantar. Media adalah perantara atau pengantar pesan dari si pengirim (komunikator atau sumber/source) kepada si penerima (komunikan atau audience/receiver).

Sedang menurut KBBI, media dapat diartikan sebagai perantara, penghubung; alat (sarana) komunikasi seperti koran, majalah, radio, televisi, film, poster, dan spanduk, yang terletak diantara dua pihak (orang, golongan, dan sebagainya).

Jadi, secara umum bisa diartikan bahwa media pembelajaran adalah alat bantu proses belajar mengajar. Yaitu segala sesuatu yang dapat dipergunakan untuk merangsang pikiran, perasaan, perhatian dan kemampuan atau ketrampilan pelajar sehingga dapat mendorong terjadinya proses belajar pada peserta didik

\subsection{Power Point}

Power Point adalah sebuah program komputer untuk presentasi yang dikembangkan oleh Microsoft di dalam paket aplikasi kantoran, Microsoft Office, selain Microsoft Word, Excel, Access dan beberapa program lainnya. PowerPoint berjalan di atas komputer PC berbasis sistem operasi Microsoft Windows dan juga Apple Macintosh yang menggunakan sistem operasi Apple Mac OS, meskipun pada awalnya aplikasi ini berjalan di atas sistem operasi Xenix. Aplikasi ini sangat banyak digunakan, apalagi oleh kalangan perkantoran dan pebisnis, para pendidik, siswa, dan trainer. (Srimaya, 2017).

Microsoft Powerpoint adalah sebuah program aplikasi microsoft office yang berguna sebagai media presentasi dengan menggunakan beberapa slide. Aplikasi ini sangat digemari dan banyak digunakan dari berbagai kalangan, baik itu pelajar, perkantoran dan bisnis, pendidik, dan trainer. Kehadiran powerpoint membuat sebuah presentasi berjalan lebih 
mudah dengan dukungan fitur yang sangat menarik dan canggih. Fitur template/desain juga akan mempecantik sebuah presentasi powerpoint. Microsoft Powerpoint adalah sebuah program aplikasi microsoft office yang berguna sebagai media presentasi dengan menggunakan beberapa slide. Aplikasi ini sangat digemari dan banyak digunakan dari berbagai kalangan, baik itu pelajar, perkantoran dan bisnis, pendidik, dan trainer. Kehadiran powerpoint membuat sebuah presentasi berjalan lebih mudah dengan dukungan fitur yang sangat menarik dan canggih. Fitur template/desain juga akan mempecantik sebuah presentasi powerpoint.

\subsection{Multimedia}

Menurut Vaughan (2011), terdapat tiga jenis multimedia, yaitu multimedia interaktif, multimedia hiperaktif, multi media linear, dan multimedia. Sedangkan menurut Sigit (2008), multimedia terbagi menjadi dua kategori, yaitu: multimedia linier dan multimedia interaktif. Multimedia Interaktif merupakan suatu alat yang dilengkapi dengan alat kontrol yang dapat dioperasikan oleh penggunanya dalam memilih sesuatu yang dikehendaki. Contoh Multimedia interaktif adalah: multimedia pembelajaran inter-aktif (pembelajaran berbasis multimedia interaktif), aplikasi game dan lain-lain.

\section{METODOLOGI PENELITIAN}

Adapun metode dari penelitian ini dapat penulis uraikan dalam bentuk diagram alur seperti dibawah ini.



Gambar 3.1 Diagram Alur Penelitian

Tahapan - tahapan rancangan penelitian :

\subsection{Identifikasi Kebutuhan}

Identifikasi kebutuhan yaitu mencoba mengetahui apa yang sebenarnya dibutuhkan dibutuhkan untuk memecahkan suatu masalah bagaiman kebutuhan yang digunakan untuk membuat suatu media pembelajaran. Biasanya setelah mengidentifikasi atau menemukan apa saja yang dibutuhkan, kita bisa menyusun prioritas kebutuhan-kebutuhan tersebut, 
misalkan kita memiliki banyak kendala dalam memenuhi kebutuhan tersebut kita dapat merumuskan kembali kebutuhan-kebutuhan tersebut untuk dicarikan solusinya.

\subsection{Perumusan Tujuan}

Perumusan tujuan adalah perumusan untuk membantu menyusun langkah-langkah penyelesaian agar lebih fokus, untuk menciptakan sebuah media pembelajaran menjadi dasar untuk menguatkan hasil penelitian sebelumnya atau menjadi dasar untuk penelitian selanjutnya, mengetahui tingkat kualitas penelitian dan memenuhi rasa ingin tahu. Dalam pengumpulan data dan informasi, pada tahap ini dilakukan untuk mengetahui mengenai sistem yang diteliti. Dari data dan informasi yang dikumpulan akan didapat data untuk pendukung penelitian. Metode yang digunakan penulis untuk pengumpulan data dengan berbagai metode sebagai berikut :

a. Observasi

Melakukan pengamatan langsung di tempat penelitian untuk mengetahui secara jelas dan terinci permasalahan yang ada. Dengan menanyakan kepuasan baik kepuasan mahasiswa maupun tindak lanjut dari dosen bagaimanaefektif dan efisiensnya dalam suatu pembelajaran.

b. Interview

Dilakukan untuk memperoleh informasi atau data yang dibutuhkan dengan cara melakukan wawancara langsung pada bagian yang terkait yaitu pada Mahasiswa, maupun dosen yang mengajar pada Universitas Islam Kuantan Singingi

c. Studi Literatur

Dalam metode ini informasi dikumpulkan dengan membaca jurnal dan buku buku yang berhubungan dengan tesis untuk menunjang dalam melakukan analisa terhadap data dan informasi. Di antara buku yang berkaitan dengan fmedia pembelajaran dan jurnal yang berkaitan dengan tesis.

\subsection{Pemngembangan Materi}

Pengembangan materi adalah serangkaian proses atau kegiatan yang dilakukan untuk menghasilkan suatu media pembelajaran berdasarkan teori pengembangan yang telah ada

\subsection{Pengembangan Alat Evaluasi}

Alat evaluasi adalah suatu yang digunakan yntuk menentukan nilai dan mutu. Merancang alat evaluasi merupakan salah satu langkah yang dharus dilakukan dosen dalam menyusun rancangan pelaksanan pembelajaran. Agar pendidik dapat menentukan keberhasilan mahasiswa dalam mencapai tujuan yang telah ditetapkan, sekaligus mengetahui efektifitas alat evaluasi yang digunakan agar gambar dan lemampuan yang dicapai harus mengikuti inovasi dan meningkatkna kinerja mahasiswa dalam memahmi pelajaran. 


\subsection{Produksi}

Produksi media merupakan segala upaya yang dilakukan untuk menciptakan dan mengolah media dengan cara mempergunakan segala sumber daya.berikut adlah upaya upaya yangdilakukan untuk memeproduksi media terutama media yang berkaitan dengan dunia pendidikan.

\subsection{Validasi}

Memvalidasi media pembelajaran adaalah tindakan atau suatu prmbuktian untuk media pemeblajaran apakah sesuai denganyang akan diajarkan kepada mahasiswa efektif dan efisiennya, dengan melihat kegiatan atau pengajaran yang diajarkan dan untuk membuktikan apakah media pembelajaran, sudah dapat untuk membantu dan digunakan oleh prndidik dan peserta didik dalam sistem pembelajaran.

\section{HASIL DAN PEMBAHASAN}

Modul pembelajaran ini dirancang dengan menggabungkan beberapa teknik, dengan harapan dapat digunakan sebagai bahan mengajar oleh dosen ketika di kelas, dan juga bisa digunakan untuk belajar secara mandiri oleh mahasiswa. Adapun tahapan - tahapan yang dilakukan dalam membuat modul ini sebagai berikut :

1. Membuat slide presentasi untuk seluruh pertemuan perkuliahan dengan menggunakan aplikasi microsoft office power point. Setiap slide masing- masing pertemuan dihubungkan ke slide utama (Halaman Depan Modul) yang akan kita gunakan untuk membuka setiap pertemuan perkuliahan. Adapun rancangan Halaman Depan Modul dapat dilihat pada gambar berikut.

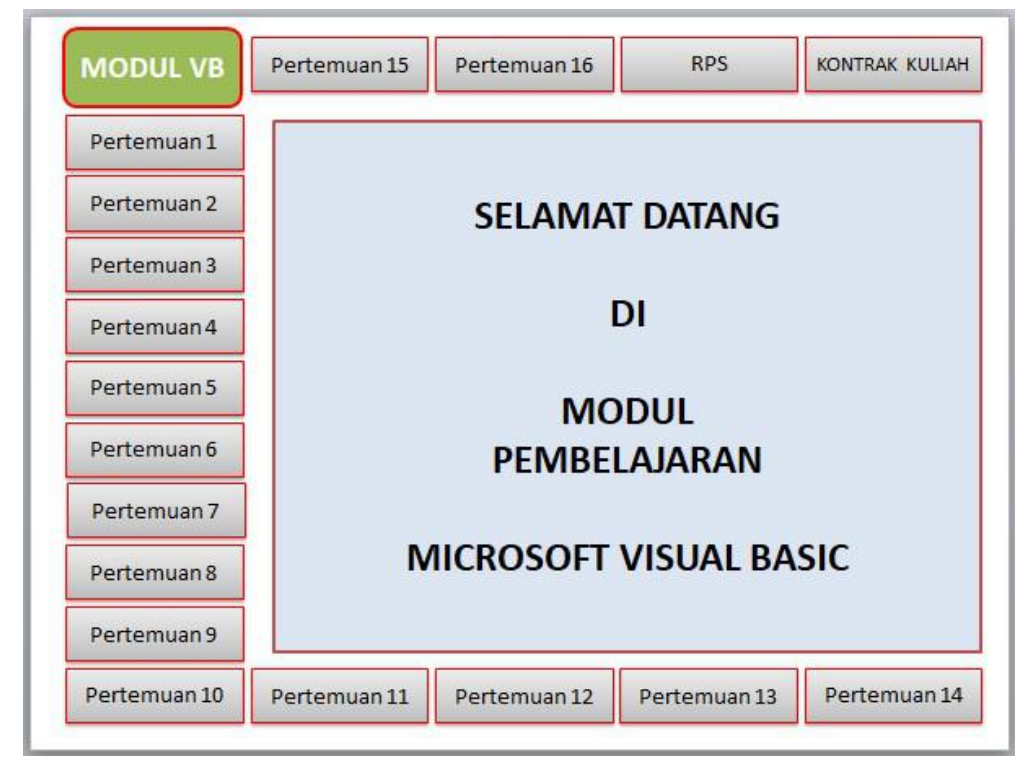

Halaman depan pada gambar di atas merupakan slide presentasi yang akan ditampilkan pertama kali ketika dosen akan mengajarkan mata kuliah. Dari gambar terlihat bahwa setiap pertemuan bisa diakses demikian juga dengan RPS dan kontrak kuliah yang harus disampaikan dosen di awal perkuliahan. Masing - masing pertemuan bisa dibuat dalam slide (file) yang sama dan bisa juga dibuat dalam file yang berbeda.

Ketika kita membuat presentasi dalam file yang sama, proses distribusi akan menjadi gampang, akan tetapi tidak efektif (lambat) jika jumlah slidenya terlalu banyak. Jika dibuat 
dalam file yang berbeda, maka kita harus mendistribusikan seluruh file agar presentasi bisa dibuka secara keseluruhan.

2. Menjelaskan masing - masing slide presentasi yang sudah dibuat menggunakan aplikasi Ispring Suite. Pada tahap ini dosen bisa menjelaskan presentasi yang sudah dibuatnya secara mandiri di rumah sebagaimana dia menjelaskan materi secara langsung kepada mahasiswanya di kelas. Dengan membuat penjelasan materi presentasi, dosen akan memiliki media pembelajaran yang sebetulnya bisa Dia gunakan untuk pengganti dirinya di kelas atau sebagai kuliah penguatan kepada mahasiswanya. Sebagaimana kita tahu, bahwa mahasiswa belum tentu mengerti ketika dosen menjelaskan di kelas, walaupun slide presentasinya diberikan kepada mahasiswa. Berikut merupakan hasil penjelasan materi presentasi menggunakan aplikasi tambahan Ispringsuite

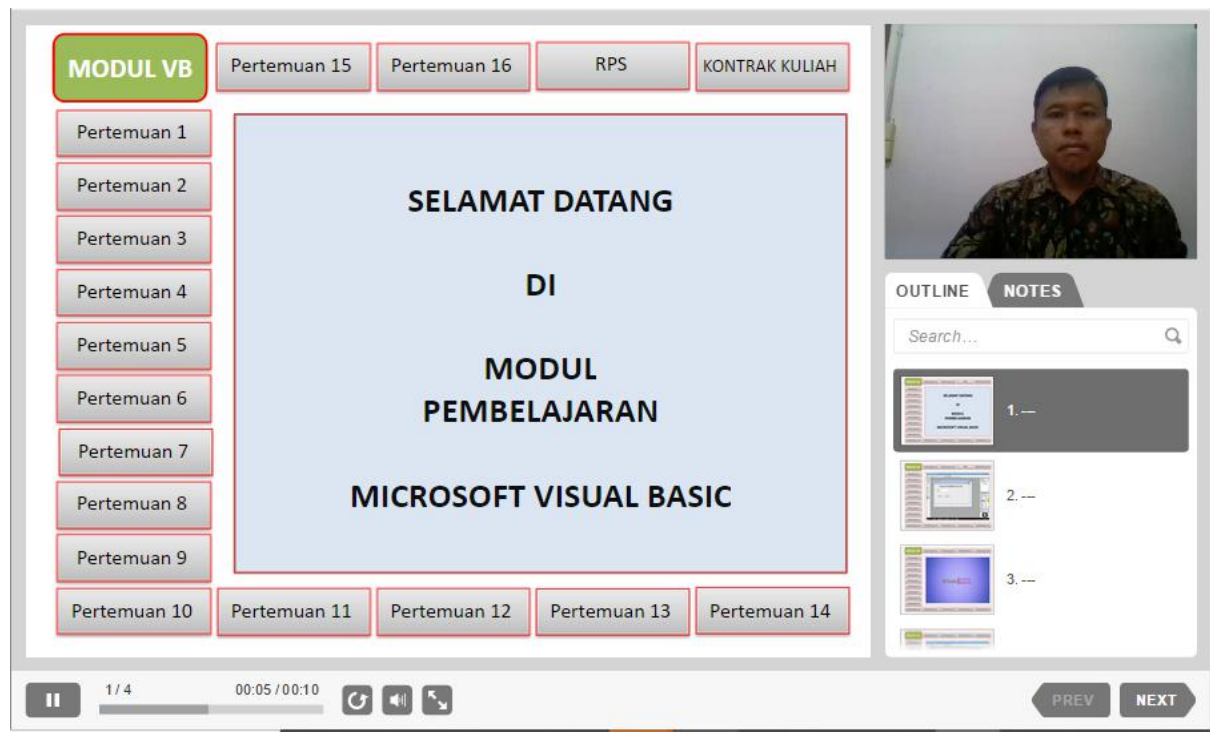

Untuk memulai media pembelajaran bisa menggunakan vidio, sehingga mahasiswa bisa belajar sendiri dirumah

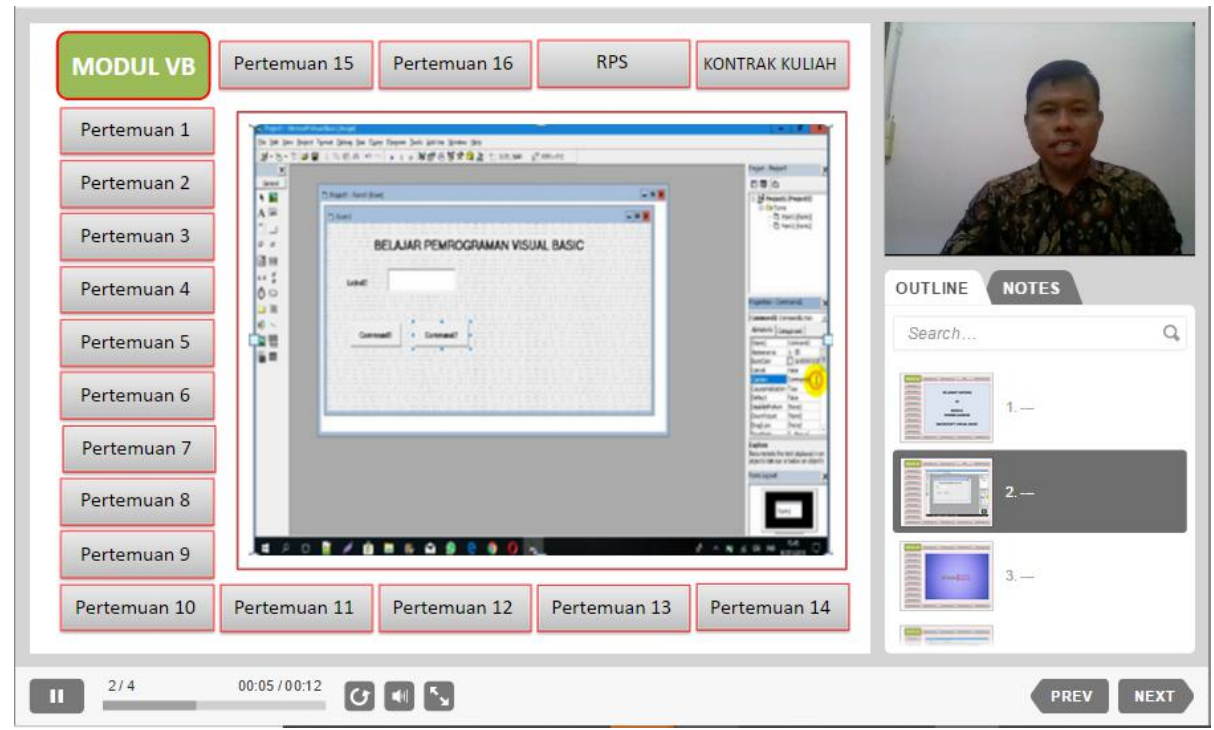



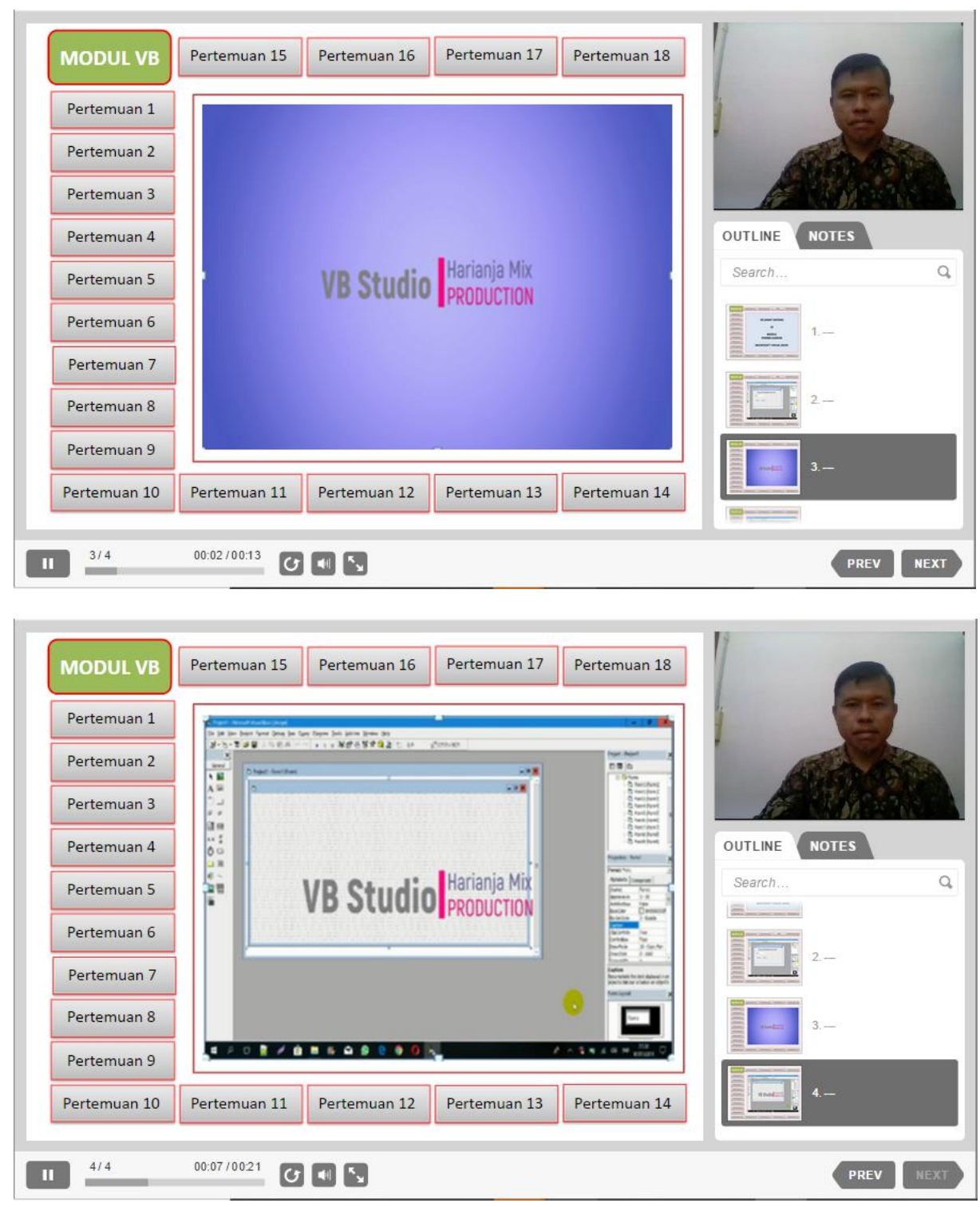

3. Merekam penjelasan masing - masing pertemuan yang sudah dibuat dengan bantuan aplikasi IspringSuite menggunakan aplikasi perekam video. Pada penelitian ini penulis menggunakan aplikasi perekam bandicam untuk merekam setiap penjelasan materi yang terdapat pada aplikasi IspringSuite. Hasil rekaman video ini, bisa kita distribusikan secara langsung kepada mahasiswa, atau diupload pada youtube pembelajaran dosen yang kemudian linknya diberikan kepada mahasiswa. Hasil rekaman videonya dapat dilihat pada gambar berikut. 

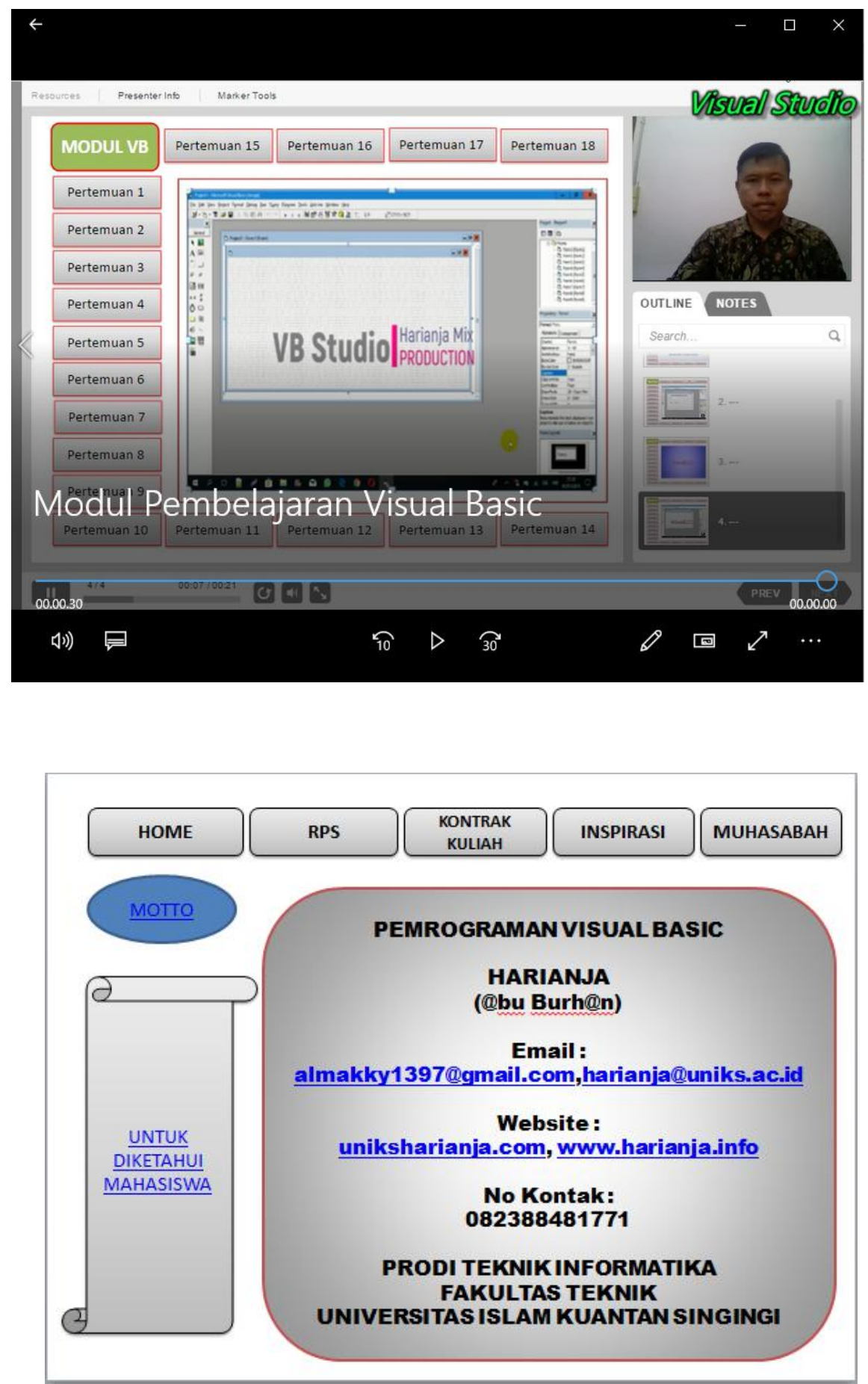


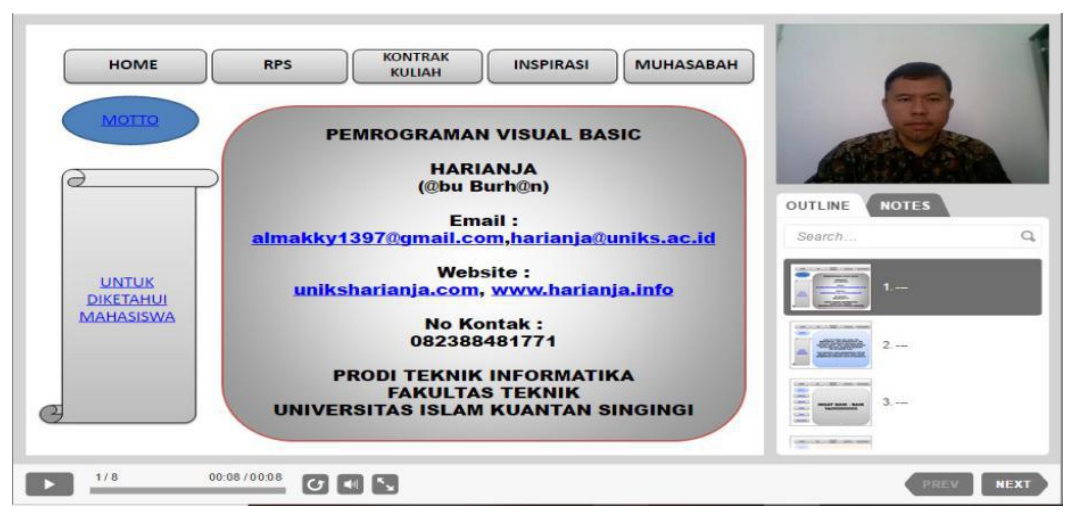

5. SIMPULAN

Dari hasil penelitian yang penulis lakukan dapat kesimpulan sebagai berikut : penggunaan media pembelajaran tidak sulit, biaya murah dan mahasiswa biasa mengulang materinya di manapun berada serta tampilanya tidak membuat mahasiswa bosan..

\section{UCAPAN TERIMAKASIH}

Alhamdulillah, puji syukur selalu peneliti panjatkan kepada Allah SWT yang telah menganugerahkan rahmat, taufik dan berkah-Nya sehingga peneliti dapat menyelesaikan dengan baik. Peneliti juga ingin menyampaikan ucapan terimakasih yang tak terhingga dan penghargaan setinggi-tingginya kepada Civitas Akademika Universitas Islam Kuantan Singingi.

\section{DAFTAR PUSTAKA}

Ali, A, J. " Sistem Security Webcame dengan Menggunakan Microsoft Visual Basic (6.0)", Jurnal Teknologi dan Sistem Informasi UNIVRAB, ISSN : 2477-2062, VOL.1 No 2, Juli 2016

A, Siska., Lifwarda., Yustini. "Pengenalan Bentuk Benda Berdasarkan Sinyal Suara dengan Transducer Mikrofon dan Teknologi Kinect", Jurnal Nasional Teknik Elektro, Vol.7, No.3, November 2018, p-ISSN: 2302-2949, e-ISSN: 2407 - 7267

Diah, D, I., NIta, S. "Media Pembelajaran Berbasis Multimedia Interaktif untuk Meningkatkan Pemahaman Konsep Mahasiswa", Journal of Computer and Information Technology, E-ISSN :2579-5317

Harianja, "Sistem Informasi Dosen Uniks Online", Jurnal Teknologi dan Open Source, E-ISSN : 2622-1659 VOL. 2 No. 2, Desember 2019

Haryanto, H., E dan Nasarim F. (2015). "Penerapan Metode Fuzzy Mamdani Dalam Memprediksi Tingginya Pemakaian Listrik (Studi Kasus Kelurahan ABC" Seminar Nasional Teknologi Informasi dan Multimedia 2015 6-8 Februari (2015), ISSN 2302-3805

Jasri. (2017). "Implementasi Fuzzy Inference System dan Pareto Optimality dalam Penentuan Interaksi Obat" Jurnal UNIKS,

Srimaya "Efektivitas Media Pembelajaran Power Point Untuk Meningkatkan Motovasi Dan hasil Belajar Biologi Siswa", Jurnal Biotek Volume 5 Nomor 1 Juni 2017 